\title{
Os limites da negociação coletiva a partir do princípio da proporcionalidade
}

The limits of collective bargaining from the principle of proportionality

\author{
Pérola Toneti de Oliveira ${ }^{1}$ \\ Lourival José de Oliveira ${ }^{2}$
}

\begin{abstract}
Resumo
Analisou-se o conflito aparente existente entre dois princípios constitucionais aplicados ao Direito do Trabalho: Proteção ao empregado e a Autonomia Privada Coletiva, a partir da tendência de abrandamento de normas protetivas ao empregado diante da relevância conferida aos acordos e convenções coletivas de trabalho. Ainda no intuito de enfatizar a importância que tem se conferido à autonomia privada coletiva na regulação da relação de trabalho, demonstrou-se a proposta de prevalência da norma negociada sobre a legislada a partir do projeto de Lei $n$ - .5.483/2001, bem como a sua rejeição, dada às críticas ao modelo sindical vigente no país e a temeridade de se precarizar as condições de trabalho diante da mitigação do princípio protetor do empregado. Assim, fez-se imprescindível apresentar a posição do Judiciário Trabalhista diante da problemática da validade de acordos e convenções coletivas sobre as normas estatais. A partir do método dialético, fora proposta a solução do impasse através da sugestão doutrinária relativa à adoção do princípio da proporcionalidade, no qual se propõe uma ponderação na superioridade que se pretende conferir a autonomia privada coletiva, de modo a observar, sobretudo, a dignidade do trabalhador, contida em regras estatais imperativas que lhe conferem proteção.
\end{abstract}

Palavras Chave: Proteção ao empregado; Autonomia privada coletiva; Sindicalismo; Negociado e Legislado; Proporcionalidade.

\begin{abstract}
We analyzed the apparent conflict between two constitutional principles applied to Labor Law: Protection of Private Collective Autonomy and the employee, from the tendency of relaxation of protective standards to the employee on the importance given to collective bargaining agreements and labor. Also in order to emphasize the importance that has been given to private autonomy in the regulation of collective employment relationship, whether the proposal demonstrated the prevalence of trading on the legislated standard from the draft law No. .5.483/2001 as well as rejection, given the criticism of the labor force in the country and the temerity to
\end{abstract}

\footnotetext{
${ }^{1}$ Acadêmica do $5^{\circ}$ ano matutino do curso de Direito da Universidade Estadual de Londrina.

${ }^{2}$ Doutor em Direito (PUC-SP); professor associado da Universidade Estadual de Londrina; professor da FACCAR; professor do Curso de mestrado em direito da UNIMAR.
} 
precarious working conditions on the principle of mitigation guard employee. Thus, it was imperative to present the position of the judiciary on the issue of Labour validity of collective agreements and conventions on the rules state. From the dialectical method, was proposed a solution to the stalemate by suggesting the adoption of the doctrine on the principle of proportionality, which proposes a weighting in the superiority that is intended to confer private collective autonomy in order to observe, above all, dignity the paper, including mandatory government rules that confer protection.

Keywords: Protection of the employee; private collective autonomy; Unionism, Trades and legislative branches; Proportionality.

\section{Introdução}

A partir do reconhecimento constitucional conferido à Autonomia Privada Coletiva, através dos instrumentos de negociação coletiva, acordos e convenções, firmou-se a possibilidade de se fazer preponderar a norma negociada sobre a legislada na regulação das condições de trabalho.

Neste contexto, fora proposta através do projeto de lei №. 5.483/2001, a alteração do art.618 da CLT, em que, se aplicaria subsidiariamente o comando legal, em razão de omissão de acordos e convenções, com ressalva aos preceitos constitucionais e normas legais específicas.

Embora o referido projeto de lei tenha sido rejeitado, o mesmo serviu para propugnar alguns debates que acabaram por resultar em vários questionamentos sobre os limites do negociado, em especial quando se tem o reconhecimento de cláusulas coletivas de trabalho pelo próprio Judiciário trabalhista em possível afronta não somente a normas expressas de ordem pública como a determinados princípios constitucionais.

Diante disso, primeiramente questionam-se os procedimentos reais de formação dessas normas coletivas negociadas por meio de uma análise crítica da situação que se encontra a organização sindical brasileira, bem como se apresenta a proposta doutrinária acerca da observância do princípio da proporcionalidade na orientação do julgador quanto aos limites da negociação coletiva, ao compatibilizar autonomia privada coletiva e proteção ao empregado. 


\section{0 princípio da proteção ao trabalhador}

No Direito do Trabalho, em decorrência da diferença apresentada pelo contrato de trabalho em comparação aos de natureza cível, firmou-se primeiramente, na doutrina e na jurisprudência, alguns princípios implícitos que orientaram a conduta do intérprete e do legislador infraconstitucional em matéria trabalhista.

Com fundamento no art.5o , I, da CF, diante da igualdade de todos os cidadãos perante a Lei, igualdade essa substancial e efetiva, e não meramente formal, assentou-se 0 fundamento do princípio da proteção ao empregado, em razão do pressuposto de que as partes celebrantes do contrato de trabalho encontram-se em posição de desigualdade jurídica por conta de suas diferenças econômicas, tornando necessário criar normas capazes de mitigar esse desequilíbrio (ARAÚJ0, 2003, p. 182).

Além da dependência econômica do empregado que, embora não constituía elemento conceitual do contrato de trabalho, quase sempre estar presente, devido à natureza alimentar do salário do empregado pago por seu empregador, pode-se elencar outras várias causas dessa desigualdade fática como a subordinação jurídica, peculiar a essa relação, que torna 0 empregado sob a autoridade de seu empregador, o poder diretivo conferido a este último que the assegura, dentro de certos limites, o direito de comandar, disciplinar, dar ordens e de modo geral até mesmo sancionar o empregado por descumprimento de ordens, o que gera a este uma condição de inferioridade, a própria pessoalidade na prestação do serviço que faz com que este, muitas vezes, se exponha a ambientes de trabalho insalubres ou perigosos, e até mesmo a ignorância do empregado em relação aos seus direitos trabalhistas em países como o Brasil, aonde 0 analfabetismo é particularmente alto (SILVA, 1999, p. 24-25).

Desse modo, diante de tantas peculiaridades que distinguem o contrato de trabalho, vê-se a importância de conferir ao empregado uma posição de superioridade jurídica na relação de emprego, sendo, assim, objetivo da Justiça do Trabalho tutelá-lo preferencialmente.

Contudo, deve-se ter cautela diante de afirmações doutrinárias que pregam que a "proteção do trabalhador é causa e fim do Direito do Trabalho" (SILVA, 1999, p. 26), pois, como bem ressalta Arion Sayão Romita, afirmar a função protecionista do direito do 
trabalho em benefício do empregado seria desconhecer a bilateralidade da relação de emprego (2002, p. 15).

Assim sendo, cabe ao Direito do Trabalho fazer com que o princípio da proteção exerça papel fundamental na orientação do intérprete das normas trabalhistas apenas equilibrando as posições econômicas dos respectivos sujeitos, e também, mediante concessão de garantias ao empregado, com o intuito não de protegê-lo, mas de realizar o ideal de justiça, compensar desigualdades ditas iniciais pela outorga de vantagens aptas a igualar as posições (LIM A, 1997, p. 34).

Desse modo, segundo a melhor doutrina, a inferioridade do empregado é consubstancial não só ao contrato como ao próprio sistema capitalista, o que faz necessária a proteção enquanto este existir, evitando, contudo, um amplo alcance deste, eis que atualmente não cabe ser aplicado isoladamente de modo a esquecer-se do meio social e das transformações a que o trabalhador se submete, não devendo, portanto desaparecer, mas, ser aplicado com prudência, de modo a não olvidar a vigência da autonomia privada coletiva, princípio este, assegurado em sede constitucional (RUPRECHT, 1995, p. 13).

\section{0 princípio da autonomia privada coletiva e a negociação coletiva}

Em contraposição ao princípio protetivo ao empregado, nascido a partir das prerrogativas conferidas aos trabalhadores no contrato de trabalho, a Constituição Federal, sobretudo após reconhecer as mudanças nas relações de trabalho de um contexto neoliberalista e aderir ao fenômeno da flexibilização no intuito de abrandar a rigidez legal, consagrou amplamente nos artigos 7ํㅡ, incisos 7으, VI, XIII, XIV, XXVI, e 8oㅡ, VI, o princípio da autonomia privada coletiva, que, segundo a doutrina, vem a ser um princípio cuja expressão do pluralismo político, por meio das negociações coletivas, assegura aos grupos sociais, empregados e empregadores, o direito de elaborar normas jurídicas a partir da fixação das condições de trabalho aplicáveis às peculiaridades do ambiente laboral (RUPRECHT, 1995, p. 85).

Desta maneira, a autonomia privada coletiva passou a conferir aos atores sociais, 0 direito a negociação coletiva através de entidades sindicais, no intuito de encontrarem um ponto convergente entre seus interesses, retirando a intervenção estatal que, alheia as 
transformações, principalmente quanto às formas de prestação do trabalho, acabava por obstaculizar a adequação do direito do trabalho à nova realidade laborativa.

Sobre o princípio, o doutrinador uruguaio Américo Plá Rodriguez diz tratar-se de um princípio valorizador da negociação coletiva, fundamentando a possibilidade de as partes poderem instituir regras aplicáveis a si mesmas (2004, p. 50).

Pedro Paulo Teixeira Manus o conceitua como sendo "o poder das entidades sindicais de auto-organização e auto-regulamentação dos conflitos coletivos de trabalho" (2007, p. 233).

A partir das conceituações expostas, vê-se que a autonomia coletiva conferida aos indivíduos significa possibilitar às organizações sindicais profissionais e patronais criarem regulamentação às relações individuais de trabalho, através do procedimento da negociação coletiva de trabalho, na qual se expressa por meio de acordos e convenções.

Surgido inicialmente por iniciativa obreira, através da expansão da atividade industrial, decorrente do desenvolvimento do capitalismo, em um contexto de liberalismo em que não se havia qualquer tutela aos direitos dos empregados, o sindicalismo, propiciou a organização de trabalhadores visando à proteção de interesses oriundos de uma mesma atividade profissional, em associações conhecidas como sindicatos. Essa organização dos trabalhadores em entidades sindicais objetivou, sobretudo, refrear as péssimas condições de trabalho a que estavam submetidos, devido ao distanciamento do Estado em matéria regulamentadora de direitos, que até então se operava, fazendo com que os empregados de uma mesma atividade profissional se unissem e reivindicassem seus direitos. Com a passagem do Estado Liberal para o Intervencionista, sobretudo nos países em que 0 corporativismo fora mais acentuado como foi o caso do Brasil, o sindicalismo continuou a existir, porém não encontrando campo fértil para desenvolver-se, eis que, passaram a ser controlados pelo Estado a partir da idéia de que caberia ao este, com o intuito de se evitar revoltas e manifestações obreiras, disciplinar as relações de trabalho colocando-se com prioridade sobre 0 interesse de determinados grupos, fazendo restringir a autonomia privada coletiva, sobretudo ao adotar sistema de sindicato único, impondo agrupamento profissional ou econômico a partir de categorias em que se reúnem indivíduos por similitude de profissão ou atividade exercida, impedindo assim, a plena associação (CUNHA, 2007, p. 227). 
Pois bem, após a modificação do Estado corporativista, em que a economia era organizada em torno deste no sentido de promover o interesse nacional, em que, sendo 0 único legitimado a cumprir os anseios sociais, se estaria suprimindo a negociação coletiva entre empregado e empregador, chegou-se ao ápice de validade dos instrumentos negociais ao ingressar o mundo do trabalho em modificações que implicariam em flexibilizar os comandos rígidos celetistas para viabilizar a aproximação entre Direito e Trabalho.

Com isso, a partir da adoção da flexibilização das normas trabalhistas pela atual Constituição, o Direito do Trabalho deixou de ser orientado pela concepção puramente protecionista, chegando a uma concepção em que a autonomia privada, através da negociação coletiva estabelecida entre empregado e empregador, romperia com postulados estruturais do Direito do Trabalho, tais como a impossibilidade de alteração contratual lesiva contida no art.468 da CLT e a inderrogabilidade dos limites legais mínimos de proteção (AUGUSTIN; ALMEIDA, 2005, p. 56).

Todavia, cabe ressaltar a importância que a negociação coletiva possui quando firmada através de organizações sindicais, E isso porque, ser somente a negociação coletiva, o instrumento hábil a expressar a vontade obreira, como afirma Dinaura Godinho Pimentel Gomes (2005, p. 186).

Diferenciando autonomia privada coletiva de negociações coletivas, João de Lima Teixeira Filho explica que a autonomia privada coletiva vem a ser um poder social constitucionalmente validado pelas disposições do art.7ํ e 8으 da CF, em que, a partir de uma "autogeração" de tutela específica para seus representados, forma-se um ordenamento não Estatal, mas reconhecido pelo Estado. Sendo a negociação coletiva, um meio pelo qual esse princípio se exercitaria, constituindo-se em um processo democrático através do qual as partesbuscam, diretamente, uma composição para a regência das relações de trabalho que protagonizam (2002, p. 1164).

A negociação coletiva, por sua vez, vem a ser um procedimento desenvolvido entre os atores sociais no intuito de discutirem seus interesses e encontrar uma forma de composição para seus litígios, sendo esta exercida através das convenções e acordos coletivos de trabalho, em que ambas as partes pactuam normas que passaram a reger a relação de trabalho, caracterizando-se assim como uma forma de solução direta de um conflito coletivo. 
Distinguindo-se as duas formas de negociação possibilitada pelo ordenamento, têm-se a convenção coletiva na qual prevê um ajuste entre um sindicato de empregados e um sindicato de empregadores, podendo haver vários sindicatos em ambas as partes, estabelecendo normas genéricas que irão vigorar pelo prazo estipulado entre as partes, devendo ser no máximo de do is anos como prevê o art.614, §3o da CLT, sendo de aplicação obrigatória a todos os contratos individuais de trabalho dos empregados e empregadores abrangidos pelos sindicatos convenientes, não podendo estes escusarem-se ao seu cumprimento (M ANUS, 2007, p. 235).

Já o acordo coletivo, apesar de estabelecer normas da mesma natureza que as convenções, em mesma imposição de limitação de vigência e de aplicação, possui aplicação mais restrita, pois é celebrado entre sindicato de empregados e uma ou mais empresas, não abrangindo toda a categoria econômica.

Desse modo, restando clara a diferença existente entre os instrumentos negociais, passa-se ao estudo da atenção conferida pelo legislador infraconstitucional à negociação coletiva.

0 projeto de lei no. 5.483 de 04 de dezembro de 2001

A Constituição Federal de 1988, como já visto anteriormente, incorporou estímulos à negociação coletiva, e adotou a tendência em se permitir, por meio dela e das entidades sindicais representativas, a modificação das garantias heterônomas dos trabalhadores, quando permitiu, por exemplo, sempre através deste instrumento negocial, a quebra da garantia de irredutibilidade salarial (art.7ํ, VI), a modificação do limite de seis horas para 0 labor em turnos ininterruptos de revezamento (art.7ํ, XIV) e a compensação de jornada (art.7ำ XIII).

Após estas implementações ao texto constitucional, foram introduzidas diversas outras formas de "flexibilização negocial", dentre elas, a Lei no 9.601/98 que autorizou a instituição de contrato de trabalho por prazo determinado, independente de motivação específica, permitindo uma ampla utilização da modalidade excepcional de duração do contrato desde que este fosse instituído mediante negociação entre os sindicatos das categorias contratantes, a compensação de jornada pelo período de um ano, como prevê a MP o..1709/1998, o trabalho em regime de tempo parcial, autorizando sua adoção 
mediante negociação coletiva e a participação nos lucros e resultados, tendo também condicionada sua implementação à mesma condição.

Ainda no que tange a essas mudanças, existiu no governo Fernando Henrique Cardoso, por iniciativa do então Ministro do Trabalho, Francisco Dornelles, a proposta de alteração do art. 618 da CLT que, conforme Projeto de Lei da Câmara no 134, de 2001 (originalmente Projeto de Lei № 5.483 aprovado pela Câmara em 04 de Dezembro), buscouse conferir atuação prática à ênfase dada pela Constituição ao instituto da negociação coletiva, objetivando assim, a prevalência do negociado sobre o legislado, sendo, entretanto, ressalvadas normas de segurança e de saúde do trabalho e os direitos constitucionais mínimos. A proposta, presente na obra de Antônio Álvares da Silva, tinha a seguinte redação:

\begin{abstract}
Art. 618. Na ausência de convenção ou acordo coletivo firmados por manifestação expressa da vontade das partes e observadas as demais disposições do Título VI desta Consolidação, a lei regulará as condições de trabalho.

Parágrafo 1ํ. A convenção ou acordo coletivo, respeitados os direitos trabal histas previstos na Constituição Federal, não podem contrariar lei complementar, as Leis № 6.321, de 14 de abril de 1976, e no 7.418, de 16 de dezembro de 1995, a legislação tributária, a previdenciária e a relativa ao Fundo de Garantia do Tempo de Serviço - FGTS, bem como as normas de segurança e saúde do trabalho (2002, p. 86).
\end{abstract}

Sob a justificativa de devolver aos atores sociais, a capacidade e a legitimidade de dirigir seus próprios interesses por meio da negociação coletiva, contida na exposição de motivos do anteprojeto de Lei, a partir da vigência desta, permitir-se-ia aos trabalhadores, por meio de sindicatos representativos da categoria profissional, mediante acordo ou convenção coletiva, até mesmo renunciarem a certos direitos previstos em legislação infraconstitucional, fazendo-se prevalecer os instrumentos negociais sobre as normas estatais.

E isso porque, conforme lembra Benedito Calheiros Bomfim:

Os sindicatos sempre foram livres para negociar condições mais benéficas aos trabalhadores do que as previstas em lei, como era comum ocorrer. Logo, a negociação coletiva visada no Projeto governamental só pode ter por objetivo a negociação prejudicial aos assalariados. Do contrário, a medida proposta seria ociosa, redundante (2003, p. 14). 
Segundo essa proposta, tudo que for decidido no âmbito da negociação coletiva teria validade, desde que permanecesse um mínimo constitucional e as normas relativas à segurança e a saúde do trabalho, ainda que contrariasse o estabelecido na CLT e, sobretudo o disposto no art.468, segundo o qual a alteração das condições dos contratos individuais de emprego só seriam permitidas diante de um mútuo consentimento e não resultasse em prejuízos ao empregado.

Assim, o verdadeiro objetivo do projeto governamental seria preservar, sobretudo, as normas constitucionais, eis que, somente modificáveis por meio de Emenda, alterando-se, porém, as normas infraconstitucionais.

Amador Paes de Almeida, em artigo científico no qual expõe as verdades e mentiras do "negociado sobre o legislado", exemplifica a proposta nos seguintes termos:

0 art. 7.0, inciso XVII, da CF/88 assegura aos trabalhadores, 0 'gozo de férias anuais remuneradas com, pelo menos, um terço a mais do que o salário normal'. 0 dispositivo constitucional, porém, não estabelece o prazo dessas férias, deixando-o a critério da lei ordinária, que o fixa em trinta dias corridos (art. 130 da CLT), dimensionando esse prazo segundo o número de faltas injustificadas ao serviço. Nos termos do art. 134 da CLT, as férias devem ser concedidas em um só período e só excepcionalmente divididas em dois períodos, um dos quais nunca inferior a dez dias corridos.Com a 'reforma', o empregador pode conceder período de férias inferior ao prazo mencionado, bastando que firme acordo nesse sentido com 0 sindicato dos seus empregados (2001).

Dessa forma, segundo essa proposta, outros direitos poderiam ser igualmente negociados, como, por exemplo, o pagamento parcelado, mês a mês, do 13. salário e até mesmo 0 previsto no art. 7.․, inciso IX, da Constituição, que consiste na "remuneração do trabalhador noturno superior à do diurno"; eis que, não havendo previsão constitucional quanto ao percentual da remuneração, a disposição infraconstitucional prevista no art.73 da CLT que o fixa em 20\%, poderia ser perfeitamente negociada, reduzindo-o.

Então, pode-se concluir que, quando, por meio de negociação coletiva, forem criadas normas convencionais que forem mais benéficas aos empregados do que as previstas na Constituição e na Lei infraconstitucional, aquelas seriam plenamente válidas. Entretanto, quando estas contrariarem disposição constitucional, seriam declaradas nulas. Desta feita, vê-se que o teor do projeto limita-se às leis infraconstitucionais, podendo, a princípio, por meio da negociação coletiva, a estipulação de normas convencionais que importem em prejuízo ao trabalhador ante as disposições estatais. Contudo, vale destacar a pergunta feita 
por Maurício Godinho Delgado quando da abordagem do assunto: "Em que medida as normas juscoletivas podem se contrapor às normas jusindividuais imperativas estatais existentes?" (2007, p. 1321), isto é, até que ponto haverá preponderância do negociado sobre o legislado? Será que com isso haveria desrespeito a legislação protetiva com previsão no caput do art. $7^{\circ}$ da Constituição, que prevê a melhoria da condição social do trabalhador?

Essa e outras questões serão pertinentemente abordadas quando do estudo dos princípios considerados pela doutrina como solução ao problema apresentado.

A rejeição do projeto de lei e os possíveis entraves à ampla autonomia privada coletiva

Como se sabe, o referido projeto de lei em que se previa uma ampla prevalência do negociado sobre o legislado fora rejeitado por parlamentares e sindicalistas, tanto pelo Congresso Nacional, como nas ruas, com passeatas em defesa da CLT em sua integralidade. Ainda sim, no dia 4 de dezembro de 2001, foi aprovado pela Câmara dos Deputados o referido projeto de Lei no 5.483/01, sendo sua aprovação noticiada na abertura da Revista LTr de dezembro/2001 nos seguintes termos:

0 projeto tem sido objeto de acirrada polêmica, quer nos meios de comunicação geral ou especializados, quer no próprio Congresso Nacional, onde o debate da matéria na Comissão de Trabalho da Câmara foi acompanhado de invasão de sindicalistas, quebra de portas, manifestações de repúdio por parte de trabalhadores, culminando com a falha do painel eletrônico do Plenário da Câmara na primeira votação, que levou ao adiamento do embate para uma semana depois. Os adversários do projeto sustentam que a filosofia da flexibilização nele inserida constituiria verdadeira derrocada de conquistas trabalhistas obtidas a duras penas, fragilizando-se o sistema protetivo insculpido na CLT. Ademais, num país de sindicalismo fraco, onde apenas algumas categorias melhor organizadas poderiam fazer frente à pressão econômica do setor patronal, seria uma temeridade abandonar os trabalhadores nas mãos de entidades sindicais que não têm condições de defender seus interesses de forma satisfatória (apud MARTINS FILHO, 2006).

Parece claro que, nesta proposta, a negociação entre sindicatos, sobretudo 0 representativo obreiro, exerça um papel fundamental ao indicar o consentimento coletivo das partes diretamente envolvidas e interessadas quando da construção de normas. De tal modo que seriam elas, que iriam estabelecer, em cada caso concreto, a autorização da contratação por tempo determinado e da instalação do banco de horas, ou a forma de participação nos lucros e resultados da empresa. 
Desse modo, ao constituir-se em um instrumento imprescindível para a eficácia jurídica dessa nova proposta, a atuação sindical acaba por legitimar o processo negocial.

Entretanto, com a eleição do Presidente Lula, o Projeto de Lei Complementar n-.134/01 (número que recebeu o PLC 5.483/01 no Senado Federal) foi retirado de pauta pelo novo governo, como afirma o Ministro do Tribunal Superior do Trabalho, Ives Gandra da Silva M artins "na esperança de que se conseguisse, com o 'Fórum Nacional do Trabalho', um consenso quanto à reforma tópica da CLT" (2006).

Quanto aos motivos que ensejaram a rejeição da proposta, tem-se apontado justamente 0 poder de negociação dos sindicatos no país, bem como os problemas apontados pela doutrina no que se refere a sua atuação e representatividade.

Sobre isso, Arion Sayão Romita observa que "o teor do projeto seria adequado a um regime democrático de regulação das relações de trabalho que atualmente se desconhece no país" (2002, p. 23-24).

0 mesmo doutrinador acrescenta ainda que a negociação digna de uma proposta de tal magnitude só encontraria efetividade diante de uma plena liberdade sindical, aonde se verificasse uma representatividade por entidades sindicais autênticas e fortalecidas, o que não seria o caso do Brasil, por não haver no país um movimento sindical que apresentasse tais características (2002, p. 23-24).

Cabe, assim, apresentar 0 atual modelo sindical existente no país, no que tange a suas características, bem como as críticas feitas pela doutrina no que se refere ao poder que se tenta conferir às entidades sindicais de construírem normas trabalhistas em detrimento da legislação estatal de proteção ao trabalho hoje existente.

Panorama geral do sindicalismo no Brasil

Em um contexto de democratização de direitos, a Constituição, expressando a importância da atividade sindical, reconheceu a celebração de acordos e convenções coletivas como direitos dos trabalhadores, afastando traços marcantes do intervencionismo estatal de inspiração corporativista que antes apresentava.

Nesse sentido, a Constituição afastou a possibilidade de intervenção do Estado, declarando a liberdade de associação sindical, sobretudo no que se refere ao poder conferido aos sindicatos para definirem as suas bases de representação e a desnecessidade 
de autorização prévia do Ministério do Trabalho para a criação de entidades sindicais (NASCIM ENTO; FERRARI; M ARTINS FILHO, 2002, p. 112). Tendo também, reforçado o papel dos sindicatos na defesa dos direitos e interesses coletivos e individuais da categoria, (art.8으, III da CF), alargando os poderes da negociação coletiva a partir da participação sindical obreira.

No entanto, mesmo com as inovações trazidas, o legislador constitucional manteve o sistema de unicidade sindical em seu art. $8^{\circ}$, II, em que se prevê a proibição em se criar mais de sindicato, profissional ou econômico, da mesma categoria, em uma mesma base territorial, tornando assim, segundo a doutrina, o texto constitucional contraditório.

Quanto a esta vedação de existência de mais de uma entidade sindical, Antônio Álvares da Silva pronuncia-se afirmando que:

A proibição de haver mais de um sindicato numa mesma base territorial é anacrônica, absurda e altamente cerceadora da liberdade sindical. É uma disposição que se vem mantendo em nosso Direito por razões corporativistas dos próprios sindicatos, pois garante a um único o monopólio da representação na mesma base territorial não inferior ao município $(2002$, p. 87).

Com isso, segundo o mesmo autor, restaria óbvio que o sindicato detentor da representação, exerceria um monopólio sindical, não precisando nem mesmo esforçar-se para uma melhor prestação de serviço, eis que não existiria concorrência (2002, p. 87).

Além do mais, ressalta Emília Simeão Albino Sako, que a experiência brasileira mostra que a unicidade sindical poderá levar à dominação das organizações sindicais por grupos manipuladores, o que acentuaria a crise da representatividade, na medida em que estas poderiam refletir as ideologias e ambições de grupos, e não, os efetivos interesses da categoria. Ficando, também, o sindicato único mais vulnerável a pressão do Governo ou dos poderosos, tornando-se fraco e sem expressão política para reivindicar direitos para a classe que representam (2007, p. 70).

Diante disso, grande parte da doutrina acredita que o pluralismo sindical, isto é, a possibilidade de coexistir mais de uma entidade sindical representativa da mesma categoria em uma mesma base territorial, deveria ser preferido à unicidade.

Porém, a mesma doutrinadora alerta que apesar de não concordar com 0 atual modelo sindical em vigor no país, a pluralidade que se pretende implantar não seria tão 
adequada e eficaz como parece ser, em razão de haver a temeridade de sobreviver apenas os sindicatos com melhor poder econômico, fazendo sucumbir sindicatos legítimos que não se curvarem às pressões econômicas.

E ainda, segundo Augustin e Almeida, a grande possibilidade de o modelo do pluralismo sindical referir-se à divisão que provocaria, no interesse coletivo, pela existência de mais de uma entidade em uma mesma base territorial representando uma mesma categoria, o que faria diminuir o seu poder de reivindicação $(2005$, p. 57).

Desse modo, vê-se que, não há entendimento doutrinário quanto ao modelo sindical mais adequado a essa nova roupagem que se pretende conferir a negociação coletiva no direito do trabalho, o que, por si só, já seria um grande entrave à preponderância do negociado, eis que, como se pode observar, até mesmo o modelo do pluralismo sindical em que se atende ao princípio da liberdade sindical oriundo da autonomia privada coletiva, tem sido muito criticado pela doutrina.

Assim, conclui-se que até hoje não fora concebido um modelo sindical perfeito que atenda as finalidades de um sistema moderno e eficiente de reivindicação e proteção de direitos dos trabalhadores subordinados ou flexíveis, o que torna a reformulação do modelo sindical, uma verdadeira condição para o alargamento dessa salutar forma de solução de conflitos coletivos de trabalho, qual seja, a negociação coletiva.

Divergências jurisprudenciais acerca da proposta do negociado sobre o legislado

Em face da rejeição da proposta do negociado sobre o legislado sugerido pelo projeto de lei de iniciativa do Executivo, os limites de tal prevalência passou a ser de competência do Judiciário Laboral, esperando-se assim que a jurisprudência possa definir a legitimidade da preponderância da autonomia privada coletiva sobre as regras de proteção ao empregado.

No entanto, como o órgão do Judiciário Trabalhista e uniformizador da jurisprudência laboral, qual seja, TST, não tem dado solução unívoca sobre a matéria, vê-se com freqüência, uma jurisprudência trabalhista oscilante, que ora faz prevalecer 0 negociado, ora cassa cláusula de acordo ou convenção coletiva que adota parâmetros diversos dos legais para disciplinar as condições de trabalho. 
Atento ao impasse jurisprudencial existente, o M inistro do TST, Ives Gandra M artins Filho, elencou inúmeras hipóteses em que o citado Tribunal tem admitido a flexibilização dos direitos trabalhistas mediante negociação coletiva. (M ARTINS FILHO, 2006).

É o caso do trabalho exercido em turnos ininterruptos de revezamento em que, mediante negociação coletiva, admiti-se o trabalho excedente a 6a diária, não havendo remuneração de trabalho extraordinário, desde que este não ultrapasse a $8^{\mathfrak{a}}$ diária permitida.

Também tem o TST firmado precedente de que o pagamento da hora in itinere, independentemente do tempo efetivamente gasto pelo empregado em condução fornecida pelo empregador limitar-se-á ao tempo previamente fixado em norma coletiva, como se vê da decisão abaixo:

HORAS "IN ITINERE" - PREFIXAÇÃO DO TEM PO EM NORMA COLETIVA.

Existindo acordo coletivo no qual se fixou número certo de horas in itinere, no caso, uma por dia, há que ser respeitado, em atenção ao contido no inciso XXVI do artigo 70 da Constituição da República. Na interpretação de acordos e convenções coletivas, prevalece o princípio do conglobamento, pelo qual as normas devem ser consideradas em seu conjunto e não de forma isolada. Isso porque, no processo de negociação coletiva, a empresa ou o respectivo sindicato patronal e 0 sindicato profissional fazem concessões mútuas, visando ao consenso, de forma que cada parte envolvida ceda em determinado ponto para auferir vantagens em outro, de modo que, ao final, estejam ambas satisfeitas com o resultado obtido.

(BRASIL. Tribunal Superior do Trabalho. Processo: RR 414.174/98.9. Relator: Min. Aloysio Corrêa da Veiga. Órgão Julgador: 1ª turma. Publicação: DJ Data 28.06.2002).

Ademais, como já exposto, inclusive jurisprudencialmente, tem se admitido 0 negociado sobre o legislado na previsão constante no $§ 10$ do art.58 da CLT, em que, por meio de negociação coletiva, o TST, entendeu como tempo em que o trabalhador não se encontra à disposição do empregador, os quinze minutos que antecedem e sucedem à jornada de trabalho ordinária, tolerando o tempo superior aos cinco minutos previstos na lei celetista.

Porém, o mesmo Tribunal, tem rejeitado a proposta de supremacia da negociação, conferindo prevalência à lei, no que se refere ao regime $12 \times 36$ horas, em que, determina-se o pagamento como extraordinária, a hora que exceder a 10ª diária.

JORNADA DE $12 X 36$ HORAS - NÃO-CONCESSÃO DE INTERVALO INTRAJORNADA HORA NOTURNA REDUZIDA - PREVALÊNCIA DOS PRECEITOS DE ORDEM PÚBLICA PREVISTOS NA CLT E DOS PRINCÍPIOS CONSTITUCIONAIS QUE RESGUARDAM OS 
DIREITOS INDISPONÍVEIS DO TRABALHADOR SOBRE A AUTONOMIA DA VONTADE DAS PARTES NO ÂMBITO DA NEGOCIAÇÃO COLETIVA.

Embora já pacificado nesta Corte 0 entendimento de que é válida a jornada especial de $12 \times 36$ horas, quando prevista em acordo ou convenção coletiva de trabalho, consoante art. 70, XXVI, da CF, não se pode reputar como lícito o ajuste que suprime ou prevê a não-concessão de intervalo para repouso e alimentação. Sem prejuízo do instrumento negocial, prevalecem os dispositivos das Seções III e IV do Capítulo II do Título II da CLT, em que se inserem os artigos 71, caput e § 2으, e 73 da CLT, que cuidam dos períodos de descanso e da hora noturna reduzida, preceitos esses de ordem pública e, portanto, de natureza cogente, que visam resguardar a saúde e a integridade física do trabalhador, no ambiente do trabalho. E, comonormas de ordem pública, estão excluídas da disponibilidade das partes, que sobre elas não podem transigir. À luz dos princípios que regem a hierarquia das fontes de Direito do Trabalho, as normas coletivas, salvo os casos constitucionalmente previstos, não podem dispor de forma contrária às garantias mínimas de proteção ao trabalhador previstas na legislação, que funcionam como um elemento limitador da autonomia da vontade das partes no âmbito da negociação coletiva. A negociação coletiva encontra limites nos direitos indisponíveis do trabalhador, assegurados na Carta Magna, e, assim, a higidez física e mental do empregado, ou seja, a preservação da saúde no local de trabalho, é princípio constitucional que se impõe sobre a negociação coletiva. Recurso de revista provido.

(BRASIL. Tribunal Superior do Trabalho. Processo: RR 785.721/2001.1. Relator: Min. Milton de Moura França. Órgão Julgador: 4a turma. Publicação: DJ Data 25.06.2004).

ACORDO DE COMPENSAÇÃO. REGIME DE 12X36. HORAS EXTRAS ALÉM DA 10aa DIÁRIA.

0 empregado submetido ao regime de compensação de 12 por 36 horas previsto em acordo ou convenção coletiva faz jus ao pagamento do adicional por trabalho extraordinário sobre as horas trabalhadas além da 10a diária. (BRASIL. Tribunal Superior do Trabalho. Processo: RR 666.554/2000.1. Relator: Min. João Oreste Dalazen. SBDI-1. Publicação: DJ Data 27.03.2006).

Da mesma forma e sobre os mesmos fundamentos, isto é, os da preservação da saúde e integridade física do trabalhador, a jurisprudência trabalhista apresenta firmado entendimento quanto a supressão ou redução do intervalo intrajornada conferida ao empregado que exerce atividade laborativa por mais de 4 horas por dia, como se vê da Orientação Jurisprudencial no.342 da SBDI - 1 do TST que diz ser inválida cláusula de acordo ou convenção coletiva de trabalho que contemple a supressão ou redução do intervalo intrajornada por constituir este medida de higiene, saúde e segurança do trabalho, tendo sido garantido por norma de ordem pública prevista no art.71 da CLT.

E por último, vale ressaltar que a tentativa de reduzir o período da estabilidade da gestante garantido pelo artigo 10, inciso II, alínea b do Ato das Disposições Constitucionais Transitórias, também não fora aceita, eis que, como bem entende a jurisprudência 
trabalhista, tal norma constitui-se imperativa e com característica puramente social visando à proteção da maternidade e do nascituro.

DISSÍDIO COLETIVO - ESTABILIDADE DA GESTANTE - ARTIGO 10, INCISO II, ALÍNEA "B", DO ATO DAS DISPOSIÇÕES CONSTITUCIONAIS TRANSITÓRIAS. O fato de a norma coletiva dispor de forma menos benéfica que a regra inscul pida no artigo 10 , inciso II, alínea b , da Constituição Federal de 1988 é capaz de justificar a sua exclusão do ajuste celebrado entre as partes. Com efeito, por se tratar de norma cogente e de caráter eminentemente social, que visa à proteção da maternidade e do nascituro, não há como se concluir pela validade de transação que reduza a mencionada garantia. A Constituição Federal de 1988 admite a flexibilização do salário e da jornada dos trabalhadores, desde que garantida a manifestação desses por intermédio de assembléia devidamente convocada. Todavia, em se tratando de normas relacionadas à proteção da maternidade (e do nascituro), estão fora da esfera negocial dos sindicatos, por serem de ordem pública, inderrogáveis pela vontade das partes e revestirem-se de caráter imperativo para a proteção do hipossuficiente, em oposição ao princípio da autonomia. Recurso Ordinário conhecido e provido.

(BRASIL. Tribunal Superior do Trabalho. Processo: RODC-796.714/01. Relator: Min. Rider Nogueira de Brito. SDC. Publicação: DJ Data 07.06.2002)

Diante da reprodução dos entendimentos dominantes extraídos do órgão máximo uniformizador da jurisprudência trabalhista no país, pode-se chegar à conclusão de que os fundamentos para se afastar o negociado sobre o legislado seriam, em essência, os mesmos do projeto de alteração do art. 618 da CLT, não se admitindo a desregulamentação legal em matéria de medicina e segurança do trabalho, legislação tributária e previdenciária.

Assim, diante da indefinição legislativa quanto aos limites e parâmetros da negociação coletiva, caberá à Justiça do Trabalho e ao TST em particular, como o intérprete máximo da legislação laboral, definir os limites para a negociação coletiva, não sendo adepto a uma total rigidez, e nem mesmo olvidando da condição subordinativa do empregado em face ao empregador, que sempre acompanhará a relação empregatícia, adequando assim, dois grandes princípios constitucionais em matéria trabalhista: 0 da proteção e 0 da autonomia privada coletiva (M ARTINS FILHO, 2006).

\section{A posição doutrinária na solução do conflito e o princípio da proporcionalidade}

Antes de finalizar o estudo do presente trabalho, a despeito de ser o mesmo entendimento da jurisprudência dominante quanto aos limites da negociação coletiva, imprescindível se faz, expor o entendimento da melhor doutrina a respeito da supremacia da norma negociada, a partir do princípio da proporcionalidade que visa integrar a 
interpretação e aplicação dos preceitos constitucionais da proteção ao empregado e da autonomia privada coletiva.

Sabe-se que, como corolário do princípio da proteção ao empregado, o princípio que prevê a aplicação da norma mais favorável diante de uma situação que importe em várias interpretações de uma norma jurídica ou em caso de conflito entre estas, entende que as normas legais seriam um mínimo inderrogável, o qual impossibilitaria a negociação coletiva firmar condições menos benéficas ao empregado do que as previstas em lei, em razão de haver peculiaridades no Direito do Trabalho que pressupõem a irrenunciabilidade de direitos legais, como se pode verificar pelo art.9o da CLT, em que se considera nula e fraudulenta qualquer disposição contra tais direitos.

A primeira vista, vê-se que, este princípio guarda certa contrariedade com o da autonomia privada coletiva, este, como se viu, muito invocado na justificativa da supremacia das normas negociadas por sindicato obreiro sobre o disposto em lei, isto é, a possibilidade de normas convencionadas entre empregado e empregador serem aplicadas em detrimento do que prevê o texto legal, mesmo em caso de estas estipularem condições menos favoráveis ao trabalhador.

Contudo, cabe observar que, não há que se falar em contradição entre os princípios constitucionais, eis que, como observa Antônio Álvares da Silva, a Carta Magna ao acolher os dois valores, objetivou a integração entre eles e não a exclusão de um em prejuízo do outro (2002, p. 81).

Com isso firma-se a legitimidade da convenção coletiva no ordenamento jurídico, tendo, inclusive, patamar constitucional. Contudo, a grande problemática incitada no presente trabalho reside justamente na compatibilização entre a possibilidade de se ter uma norma oriunda de um processo negocial que afasta a aplicação de regras consolidadas em lei, o que vem ganhando aceitação na doutrina e, sobretudo na jurisprudência, e o preceito que prevê a proteção ao empregado ao dispor a irrenunciabilidade e inafastabilidade de normas legais.

Essa possibilidade de conciliação entre tais princípios, segundo a doutrina, apenas encontra solução no princípio da proporcionalidade, em razão de que, a harmonização de princípios fundamentais aparentemente conflitantes somente se estabelecerá diante de uma ponderação dos interesses postos em causa, no sentido de que os valores a serem 
discutidos (proteção x autonomia), possam ser colocados em uma chamada "linha de interesse", de modo a preponderar um ou outro de acordo com o interesse em questão, devendo, todavia, haver certo bom senso no sentido de evitar excessos nessa valoração, para que um princípio não seja afetado mais do que o necessário para a vigência do outro (SILVA, 2003, p. 14-29).

Este princípio da proporcionalidade ou também conhecido como razoabilidade ou princípio da proibição do excesso, tem sede na Constituição de 1988, sendo principalmente diretriz de interpretação da lei conforme o texto constitucional e seus princípios, com ampla aceitação na doutrina e jurisprudência, como meio de solução de conflitos entre princípios constitucionais, vez que objetiva orientar decisões razoáveis e moderadas que visam conferir vigência a princípios constitucionais segundo o interesse em questão que mais prepondera. Ou, em outras palavras, como afirmam os doutrinadores Carlos Pereira de Souza e Patrícia Sampaio:

0 princípio da proporcionalidade diz respeito a um sistema de valoração, na medida em que ao se garantir um direito muitas vezes é preciso restringir outro, situação juridicamente aceitável somente após um estudo teleológico, no qual se conclua que 0 direito juridicamente protegido por determinada norma apresenta conteúdo valorativamente superior ao restringido. 0 juízo de proporcionalidade permite um perfeito equilíbrio entre o fim almejado e o meio empregado, ou seja, o resultado obtido com a intervenção na esfera de direitos do particular deve ser proporcional à carga coativa da mesma (2004).

Dessa forma, seria justamente este princípio da proporcionalidade que iria estabelecer os limites da negociação coletiva quanto à preponderância das normas negociadas sobre as legais, fazendo com que, como hoje se verifica pela prática jurisprudencial, haja uma ponderação ou razoabilidade nessa superioridade que se pretende conferir, de maneira a não olvidar a vigência da proteção ao empregado pelo excesso que se pode cometer ao inobservar regras de proteção mínima que lhe conferem dignidade.

Pois, como bem observa Ingo Wolfgang Sarlet, o princípio da proporcionalidade que visa à harmonização de valores fundamentais em conflito, sugere que o limite, isto é, o excesso que se visa proibir, seja, reconduzido ao princípio fundamental do respeito e da proteção da dignidade da pessoa humana, que segundo o autor, constitui orientador de toda a ordem constitucional, sem a qual, a humanidade perderia sua razão de ser (2001, p. 378). 
Desta maneira, segundo o melhor entendimento, proibir-se-ia o excesso e julgar-seia de maneira ponderada, o julgador que não atribuir superioridade a uma norma convencionada que contrarie a proteção aos direitos mínimos que visam assegurar a dignidade da pessoa humana.

Pois, como também expõe Marcelo Pereira da Silva, devem ser observadas as diretrizes da ponderação entre direitos, que vise a uma menor afetação do indivíduo e maior preservação do direito fundamental da dignidade humana (2003, p. 38).

Os limites da proposta flexibilizatória a partir da razoabilidade

Se 0 entendimento doutrinário e jurisprudencial converge para os limites da superioridade da negociação coletiva a partir do respeito à dignidade da pessoa humana, pode-se concluir que, não prevalece, à luz do princípio da proporcionalidade, a validade jurídica de normas autônomas coletivas em face de normas heterônomas imperativas, em razão de estas serem oriundas da expressão do interesse público que visa assegurar um mínimo de direitos que não podem ser reduzidos sob pena de afrontarem a dignidade da pessoa humana (DELGADO, 2007, p. 1323).

Nesse ínterim, segundo Antônio Álvares da Silva, vê-se que os comandos de ordem pública ou imperativos não podem ser negociados (2002, p. 93). Isso porque, de acordo com Américo Plá Rodriguez, leis de ordem pública ou imperativas, expressam o que o Estado julga imprescindível e essencial para a sobrevivência da própria sociedade caracterizando-se por um conjunto de condições fundamentais da vida social, as quais, afetam a organização desta, não podendo ser alteradas pela vontade dos indivíduos (2004, p. 152).

Sobre normas de ordem pública, Maurício Godinho Delgado apresenta o que denomina de "patamar civilizatório mínimo", isto é, normas que asseguram um mínimo de proteção ao empregado que não podem ser renunciadas por meio de processo negocial, a partir de três grupos de normas trabalhistas heterônomas: as normas constitucionais em geral, sendo respeitadas as ressalvas feitas expressamente pela própria Constituição (art.7º, $\mathrm{VI}$, XIII e XIV), as normas de tratados e convenções internacionais que vigoram no ordenamento pátrio (art.5, §2을 da CF) e as normas legais infraconstitucionais que asseguram patamares de cidadania e dignidade ao indivíduo, como os preceitos relativos à 
saúde e segurança no trabalho, normas concernentes a bases salariais mínimas, dispositivos antidiscriminatórios e as demais leis de natureza imperativa (2007, p. 1323).

Até mesmo doutrinadores como Emília Simeão Albino Sako, que entendem que a regra de que a preponderância da lei de ordem pública não permite negociações menos favoráveis ao trabalhador em se tratando de direitos indisponíveis, é considerada relativa, em razão de que, ausente o prejuízo, a negociação poderia avançar em diferentes direções, acaba por se render a realidade, ao afirmar que o grande responsável pelo avanço dos direitos trabalhistas, isto é, os sindicatos, como já antes mencionado, possuem estrutura e representatividade que não correspondem com as expectativas de um sistema eficiente de reivindicação e proteção dos trabalhadores, o que, prevalecer o negociado sobre essas condições seria precarizar o direito do trabalho, inobservando o princípio protetivo (2007, p. 56-77).

Desse modo, o melhor entendimento doutrinário e também jurisprudencial, acerca do conflito, leva a conclusão de que não prevalece a norma negociada sobre direitos imantados por interesse público, não sendo passíveis de negociação sindical, relegando assim, às hipóteses de possibilidade de validade e eficácia das normas autônomas coletivas em face das normas legais, em casos em que, aquelas, implementam condições mais benéficas do que as previstas por estas últimas, ou, em caso de normas convencionais sobreporem-se a normas legais consideradas como dispositivas, ou de indisponibilidade relativa (DELGADO, 2007, p. 1322) eis que, neste caso, o interesse que se visa preponderar vem a ser o da legitimidade do reconhecimento das convenções coletivas, que aqui, entende-se não afetar excessivamente a proteção inerente ao empregado, como no caso já exposto, em que se considera válida a norma coletiva que supera os cinco minutos previstos em lei, reconhecendo em até quinze minutos excedente à jornada, tempo em que o empregado não se encontra a disposição do empregador.

Por fim, conclui-se, que, a partir dessa ponderação de princípios, em que se objetiva decisões no sentido de prevalecer norma negociada ou legal de acordo com o interesse em questão, não há que se falar em incompatibilidade entre o princípio da proteção ao empregado e o da autonomia privada coletiva no que se refere a proposta de preponderância de normas negociadas sobre as estatais, desde que, as cláusulas resultantes desses instrumentos negociais estejam sujeitas aos critérios de análise de interesse, 
mediante proibição de normas excessivas ou irrazoáveis, assim consideradas, que atentam contra interesse público que emana das normas imperativas trabalhistas (SILVA, 2003, p. 38).

Desse modo, enquanto não se definir claramente os limites da negociação coletiva, a busca por esse elemento de ponderação entre os princípios constitucionais, acaba por ser uma orientação aos operadores do direito como um critério interpretativo já percebido na prática do Tribunal Superior do Trabalho ao enfrentar a problemática da vigência de duas grandes fontes de direito do trabalho: a norma estatal e a norma negociada.

\section{Conclusão}

0 estudo do tema proposto encontra relevância e atualidade na necessidade de "conciliação prática", sobretudo em âmbito jurisprudencial, entre os princípios da Proteção ao empregado e o da Autonomia Privada Coletiva, após o amplo reconhecimento que se tem dado aos instrumentos de negociação coletiva a partir da Constituição Federal de 1988. Para tanto, fez-se mister apresentar o princípio protetivo expondo seus fundamentos e as peculiaridades existente no direito do trabalho que justificam a sua invocação, além do princípio da autonomia privada coletiva, que, após ter sido reconhecido constitucionalmente, fez com que o Direito do Trabalho deixasse de ser orientado pela concepção puramente protecionista, e reconhecesse ampla validade aos acordos e convenções coletivas firmadas entre empregado e empregador.

Além disso, no que tange à Autonomia Privada Coletiva, apresentou-se o projeto de Lei $n-5.483 / 2001$, o qual, por meio da alteração do dispositivo contido no art.618 da norma celetista, objetivou conferir praticidade à ênfase dada pela Constituição ao instituto da negociação coletiva, propondo a preponderância da norma negociada sobre a legislada, bem como a sua rejeição, apontando-se como justificativa o modelo sindical vigente no país, hoje considerado pouco representativo e com inúmeras críticas à sua estrutura organizacional, concluindo-se que os sindicatos existentes não teriam condições de conferir ampla validade às negociações coletivas, diante da temeridade de se assim proceder, acabar por precarizar as condições de trabalho.

A partir da rejeição do projeto, verificou-se grande oscilação jurisprudencial, decidindo os Tribunais pátrios, ora por conferir validade a acordos e convenções coletivas, 
ora por fazer preponderar o princípio protetor do empregado, negando vigências às normas negociais que introduzem condições menos benéficas às presentes nas normas legais.

Com base nisso, após chegar-se à conclusão de que o Judiciário Trabalhista permite essa preponderância do negociado observando-se as normas imperativas de segurança e saúde do trabalho, apresentou-se a solução proposta pela doutrina através do princípio da proporcionalidade, estabelecendo os limites da negociação coletiva, através de uma ponderação ou razoabilidade na superioridade que se pretende conferir a autonomia privada coletiva, de maneira a não negar vigência à proteção ao empregado pelo excesso que se pode cometer ao inobservar regras imperativas que lhe conferem dignidade.

Firmou-se assim, o entendimento de que a autonomia privada coletiva possível, não acarreta a revogação ou a exclusão de normas que tutelam a dignidade do empregado, mas apenas a modificação de normas legais dispositivas, mediante negociação coletiva, adequando-as a nova realidade social, firmando-se assim em uma maneira viável de introduzir as mudanças na ordem jurídica trabalhista, fazendo com que haja uma convivência entre as leis básicas de proteção ao empregado e os acordos e os instrumentos de negociação coletiva.

\section{Referências}

ALM EIDA, Amador Paes de. 0 negociado sobre o legislado - verdades e mentiras. Disponível em: 〈ttp://www.saraivajur.com.br/DoutrinaArtigosDetalhe.cfm?doutrina=198>. Acesso em: 15 maio 2008.

ALM EIDA, Ângela; AUGUSTIN, Sérgio. Reforma sindical: autonomia privada coletiva, flexibilização e pluralismo sindical. Revista Trabalho e Ambiente, Caxias do Sul, v. 4, n. 7, p. 56-57, jul./dez. 2006.

ARAÚJO, Eneida M elo Correia de. As relações de trabalho, uma perspectiva democrática. São Paulo: LTr, 2003.

BOM FIM , Benedito Calheiros. Norma legislada e norma negociada: limites e possibilidades. Revista de Direito do Trabalho, São Paulo, ano 29, n. 109, p. 14, jan./mar. 2003.

BRASIL. Constituição (1988). Constituição da República Federativa do Brasil. Brasília, DF, 1988.

CUNHA, Maria Inês Moura S.A. da. Direito do Trabalho. 4. ed. rev. atual. São Paulo: Saraiva, 2007. 
DELGADO, Maurício Godinho. Curso de Direito do Trabalho. 6. ed. São Paulo: LTr, 2007.

GOM ES, Dinaura Godinho Pimentel. Direito do Trabalho e dignidade da pessoa humana, no contexto da globalização econômica, problemas e perspectivas. São Paulo: LTr, 2005.

LIM A, Francisco M eton Marques de. Os Princípios de Direito do Trabalho na Lei e na Jurisprudência. 2. ed. rev. ampl. São Paulo: LTr, 1997.

M ANUS, Pedro Paulo Teixeira. Direito do Trabalho. 11. ed. São Paulo: Atlas, 2007.

M ARTINS FILHO, Ives Gandra da Silva. Valorização da negociação coletiva e flexibilização das normas legais trabalhistas. Revista Jurídica disponível em «ttp://www.planalto.gov.br/ccivil_03/revista/revistajuridica/index.htm>. Acesso em: 20 maio 2008.

NASCIM ENTO, Amauri M ascaro; FERRARI, Irany; M ARTINS FILHO, Ives Gandra da Silva. História do trabalho, do direito do trabalho e da justiça do trabalho. Uma homenagem à Armando Casimiro Costa. 2. ed. São Paulo: LTr, 2002.

RODRIGUEZ, Américo Plá. Princípios de Direito do Trabalho. GIGLIO, Wagner D (Trad.). 3. ed. atual. São Paulo: LTr, 2004.

ROM ITA, Arion Sayão. Princípios em conflito: Autonomia Privada Coletiva e Norma mais favorável - 0 negociado e o legislado. Revista de Direito do Trabalho, São Paulo, ano 28, n. 107, p. 23-24, jun./set. 2002.

RUPRECHT, Alfredo J. Os Princípios do Direito do Trabalho. CUNHA, Edílson Alkmin (Trad.). São Paulo: LTr, 1995.

SAKO, Emília Simeão Albino. A atuação dinâmica e eficiente dos sindicatos como garantia de realização dos direitos fundamentais e sociais dos trabalhadores. Revista de Direito do Trabalho, São Paulo, ano 33, n. 126, p. 70, abr./jun. 2007.

SARLET, Ingo Wolfgang. A eficácia dos direitos fundamentais. 2. ed. rev. atual. Porto Alegre: Livraria do Advogado, 2001.

SILVA, Antônio Álvares da. Flexibilização das relações de trabalho. São Paulo: LTr, 2002.

SILVA, Luiz de Pinho Pedreira da. Principiologia do Direito do Trabalho. 2. ed. São Paulo: LTr, 1999.

SILVA, M aurício Pereira da. "A aplicação do princípio da proporcionalidade para solução dos conflitos entre direitos sociais, na perspectiva da flexibilização dos direitos trabalhistas e princípios do direito do trabalho". In: HASSON, Roland (Coord.). Direito dos Trabalhadores \& Direitos Fundamentais. Curitiba: Juruá, 2003. 
SOUZA, Carlos Affonso Pereira de; SAM PAIO, Patrícia Regina Pinheiro. 0 princípio da razoabilidade e o princípio da proporcionalidade: uma abordagem constitucional. Disponível em: ঝttp://www.puc-rio.br/sobrepuc/depto/direito/pet_jur/cafpatrz.html>. Acesso em: 27 maio 2008.

TEIXEIRA FILHO, João de Lima. In: SUSSEKIND, Arnaldo et al. Instituiç̧ões de direito do trabalho. 20.ed. São Paulo: LTr, 2002. v.1. 